Article

\title{
Plant-Produced Anti-Enterovirus 71 (EV71) Monoclonal Antibody Efficiently Protects Mice Against EV71 Infection
}

\author{
Kaewta Rattanapisit ${ }^{1,+}$, Zhang Chao ${ }^{2,+}$, Konlavat Siriwattananon ${ }^{1}$, Zhong Huang ${ }^{2, *}$ and \\ Waranyoo Phoolcharoen ${ }^{3, *}$ \\ 1 Research Unit for Plant-Produced Pharmaceuticals, Chulalongkorn University, Bangkok 10330, Thailand; \\ Kaewta.T@chula.ac.th (K.R.); 6176452333@student.chula.ac.th (K.S.) \\ 2 Vaccine Research Center, CAS Key Laboratory of Molecular Virology \& Immunology, Institut Pasteur of \\ Shanghai, Chinese Academy of Sciences, Shanghai 200031, China; chaozhang@ips.ac.cn \\ 3 Research Unit for Plant-Produced Pharmaceuticals and Department of Pharmacognosy and Pharmaceutical \\ Botany, Faculty of Pharmaceutical Sciences, Chulalongkorn University, Bangkok 10330, Thailand \\ * Correspondence: huangzhong@ips.ac.cn (Z.H.); Waranyoo.P@chula.ac.th (W.P.); Tel.: +21-5492-3067 (Z.H.); \\ +66-2218-8359 (W.P.) \\ + These authors contributed equally to this work.
}

Received: 15 October 2019; Accepted: 21 November 2019; Published: 1 December 2019

\begin{abstract}
Enterovirus 71 (EV71) is the main causative agent of severe hand-foot-mouth disease. EV71 affects countries mainly in the Asia-Pacific region, which makes it unattractive for pharmaceutical companies to develop drugs or vaccine to combat EV71 infection. However, development of these drugs and vaccines is vital to protect younger generations. This study aims to develop a specific monoclonal antibody (mAb) to EV71 using a plant platform, which is a cost-effective and scalable production technology. A previous report showed that D5, a murine anti-EV71 $\mathrm{mAb}$, binds to VP1 protein of EV71, potently neutralizes EV71 in vitro, and effectively protects mice against EV71 infection. Herein, plant-produced chimeric D5 (cD5) mAb, variable regions of murine D5 antibody linked with constant regions of human IgG1, was transiently expressed in Nicotiana benthamiana using geminiviral vectors. The antibody was expressed at high levels within six days of infiltration. Plant-produced cD5 retained its in vitro high-affinity binding and neutralizing activity against EV71. Furthermore, a single dose $(10 \mu \mathrm{g} / \mathrm{g}$ body weight) of plant-produced cD5 mAb offered 100\% protection against infection in mice after a lethal EV71 challenge. Therefore, our results showed that plant-produced anti-EV71 mAb is an effective, safe, and affordable therapeutic option against EV71 infection.
\end{abstract}

Keywords: enterovirus 71 (EV71); hand-foot-mouth disease; plant biotechnology; monoclonal antibody; molecular pharming; plant-produced monoclonal antibody; Nicotiana benthamiana

\section{Introduction}

Hand-foot-mouth disease (HFMD) mainly affects children under five-years-old. HFMD is of considerable public health concern in the Asia-Pacific region because of the economic burden in the affected countries. In addition to hospital expenditure, loss of time from work is an additional cost, because families have to care for the sick children away from school [1]. Considering the economic burden of HFMD, the development of HFMD vaccine and a therapeutic drug is required urgently.

HFMD is caused by several viruses such as enterovirus 71 (EV71) and coxsackieviruses [2]. EV71 causes severe central nervous system or cardiovascular complications, leading to the death of infected patients [3,4]. Various types of EV71 vaccines have been developed previously, such as inactivated whole-virus vaccines [5-9], live attenuated vaccines [10,11], recombinant vaccines [12-15], and peptide 
vaccines [16,17]. For EV71 post-exposure treatment in patients with severe infection, EV71-specific intravenous immunoglobulins are used [18]. However, there are disadvantages to using pooled human sera, such as the risk of transmitting human pathogens, availability of donors, and batch-to-batch variability [19]. Therefore, neutralizing monoclonal antibodies (mAbs) are considered a safe alternative for passive immunization against EV71.

Over the years, several EV71-neutralizing antibodies have been reported [20-26]. Among these $\mathrm{mAbs}$, D5 is one of the most promising $\mathrm{mAb}$ for development as prophylactic and therapeutic for EV71 infection. D5 mAb binds specifically to SP70 peptide on VP1 GH loop of EV71 and can potently neutralize EV71 infection by blocking viral attachment and internalization and by stabilizing the virus through a bivalent binding mode [26,27]. However, the antibody production in mammalian cell culture has limitations with high production costs and scalability.

Recently, plants are being used as an alternative $\mathrm{mAb}$ production platform with unique advantages such as low production cost, speed of production, and scalability [28]. This platform offers a solution for developing countries to develop affordable medicines in the region. Previous studies demonstrated the efficacy of plant-produced mAbs for viral infections, such as West Nile virus [29], Ebola virus [30], Rabies virus [31], and others. The goal of this study is to investigate the protective effect of plant-produced EV71 specific $\mathrm{mAb}$ against EV71 challenge in mice.

In this study, chimeric D5 (cD5) mAb was constructed and produced transiently in Nicotiana benthamiana leaves. After protein-A affinity chromatography, the purified antibody was tested for binding, neutralization, and protection against EV71 infection. The plant-produced cD5 mAb bound to its epitope, SP70, and effectively neutralized EV71 and protected mice against EV71 lethal challenge. Our data confirmed that the plant platform is a promising antibody production system for producing effective mAbs for the post-exposure treatment of EV71 infection.

\section{Results}

\subsection{Expression of $c D 5 m A b$ in Nicotiana benthamiana}

To construct chimeric $\mathrm{mAb}$, variable regions of murine D5 antibody were linked with constant regions of human IgG1 heavy chain (HC) and kappa light chain (LC) and then separately cloned into a geminiviral vector, resulting in pBYD5-HC and pBYD5-LC (Figure 1). N. benthamiana leaves were agro-coinfiltrated with both $\mathrm{pBYD5-HC}$ and pBYD5-LC. In a time-course experiment, leaf samples were harvested 2-, 4-, 6-, and 8-days after infiltration. The leaves infiltrated with pBYD5-HC and pBYD5-LC showed necrosis on the sixth day after infiltration (Figure 2A). The amount of chimeric D5 (cD5) mAb expressed in N. benthamiana leaves was measured using ELISA. The optimal harvest time is six days after infiltration, and the expression level of cD5 mAb is $50 \mu \mathrm{g} / \mathrm{g}$ of fresh leaf weight (Figure 2B).

\subsection{Purification of $c D 5 m A b$ from $N$. benthamiana Leaves}

A simple, standard protein-A affinity chromatography was used to purify cD5 mAb from $\mathrm{N}$. benthamiana leaves. After the extraction process, plant crude proteins were filtered using $0.45 \mu \mathrm{m}$ filters and separated by protein-A chromatography. The purified cD5 protein sample was characterized by SDS-PAGE and western blot analysis. Under reducing condition, the heavy chain and light chain of cD5 mAb bands were present at $50 \mathrm{kDa}$ and $25 \mathrm{kDa}$, respectively (Figure 3A). Western blot analysis with anti-human gamma and anti-human kappa antisera confirmed the expression of heavy and light chain, respectively (Figure 3B,C). Under the non-reducing condition, the purified cD5 mAb band was visible at $150 \mathrm{kDa}$ (Figure 3D), confirming the assembly of the whole IgG molecule (two heavy chains and two light chains). Western blot analysis with anti-human IgG and anti-human kappa antisera confirmed the expression of the heavy chain and light chain in the whole IgG molecule (Figure 3E,F). The purified cD5 mAb was used for further in vitro and in vivo studies. 


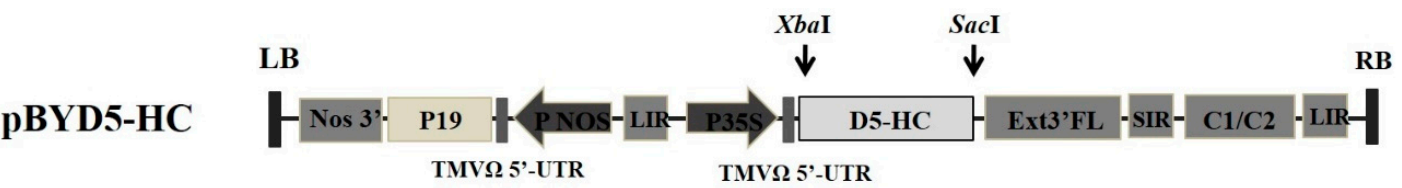

pBYD5-LC

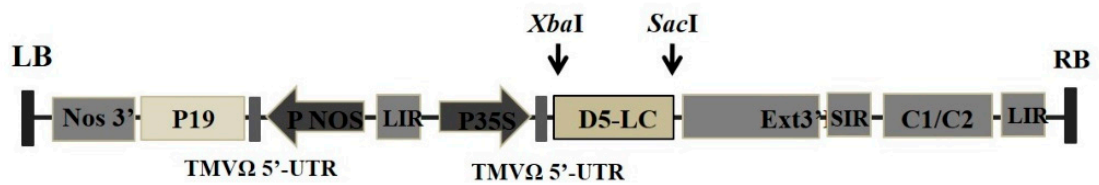

Figure 1. Constructs of chimeric D5 (cD5) heavy chain and light chain genes in geminiviral vectors used in the study. P35S: Cauliflower Mosaic Virus (CaMV) 35S promoter, TMV $\Omega$ 5'-UTR: 5' untranslated region of tobacco mosaic virus $\Omega$, D5-HC: heavy chain of cD5 antibody, D5-LC: light chain of cD5 antibody, Ext3'FL: 3' full length of tobacco tabacum extension gene, SIR: short intergenic region of BeYDV genome, LIR: long intergenic region of BeYDV genome, C2/C1: Bean Yellow Dwarf Virus (BeYDV) ORFs C1 and C2 which encode for replication initiation protein (Rep) and RepA, PNOS: nopaline synthase promoter, P19: P19 gene from Tomato Bushy Stunt Virus (TBSV), Nos3': 3' termini of the polyadenylated nos mRNA.

A

B
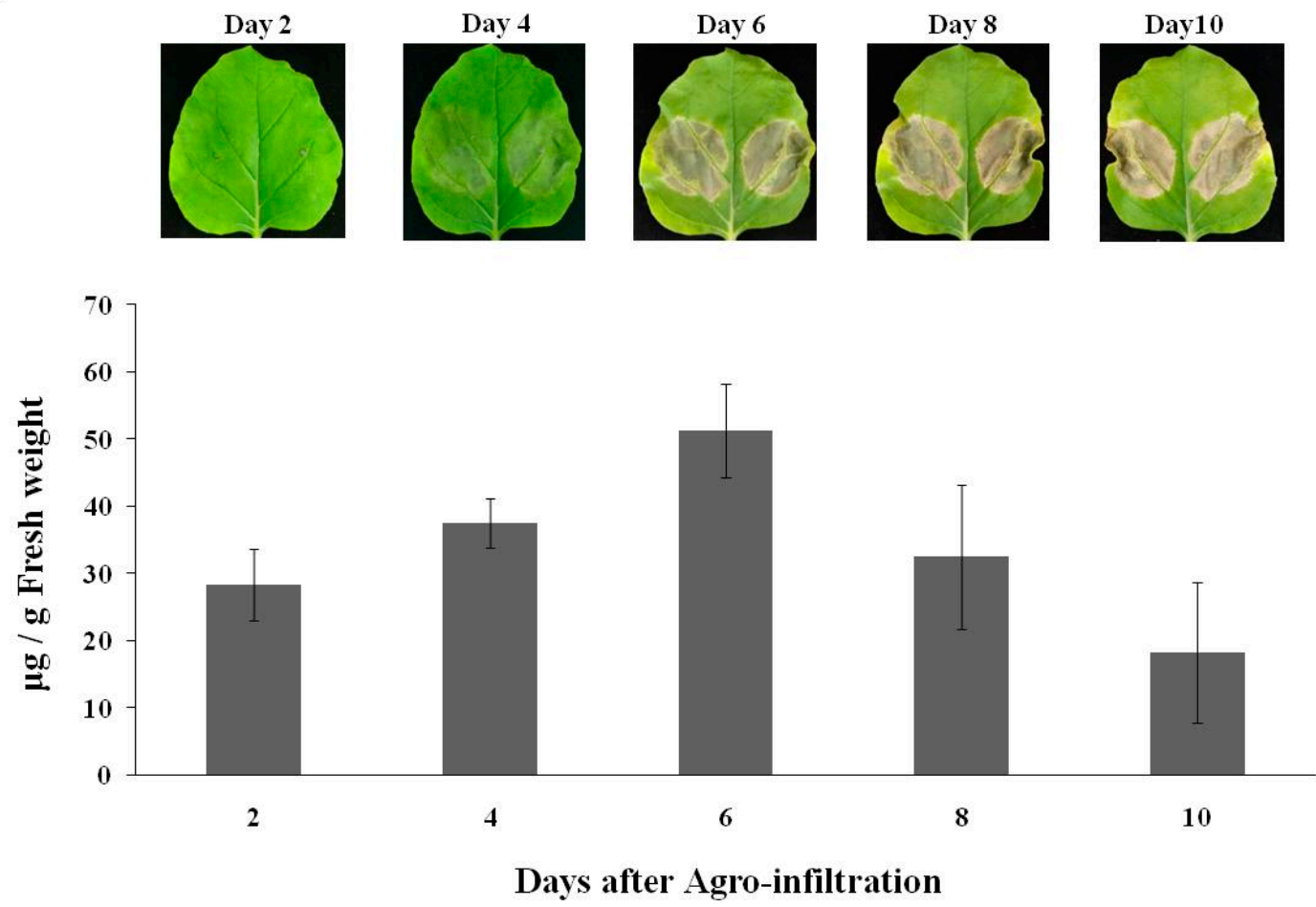

Figure 2. Day optimization of $\mathrm{cD} 5 \mathrm{mAb}$ expression in $N$. benthamiana leaves. Quantification of plant-produced cD5 mAb was determined on day 2, 4, 6, 8, and 10 after agroinfiltration using ELISA. The leaf necrosis $(\mathbf{A})$ and yield of $\mathrm{cD} 5 \mathrm{mAb}(\mathbf{B})$ were shown. Data are means \pm SD of triplicates.

\subsection{Plant-Produced cD5 mAb Retains Antigen-Binding Activity}

The purified plant-produced cD5 mAb was tested for binding in ELISA using synthetic SP70 peptide. Plant-produced cD5 mAb or human IgG control antibody (Abcam, Cambridge, UK) was serially diluted before incubation with immobilized SP70 peptide. The binding was detected by horseradish peroxidase (HRP) labeled anti-human IgG antiserum at an absorbance of $450 \mathrm{~nm}$ (OD450). As shown in Figure 4, plant-produced cD5 mAb showed saturable dose-dependent binding to SP70 peptide. By contrast, IgG control antibody did not show any binding activity, regardless of antibody 
dose. These results indicate that plant-expressed cD5 mAb has the ability to bind to the SP70 epitope recognized by murine D5.

A

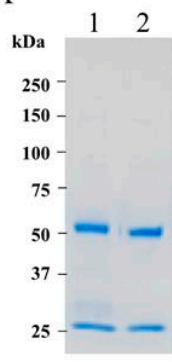

D

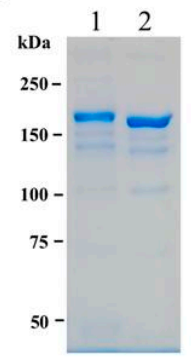

B

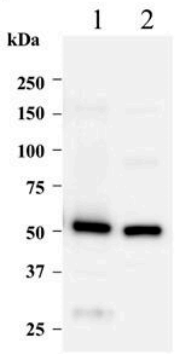

E

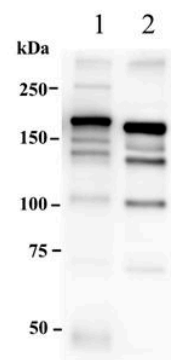

C

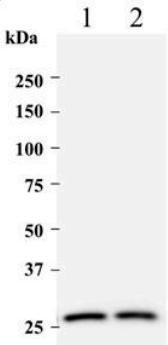

$\mathrm{F}$

12

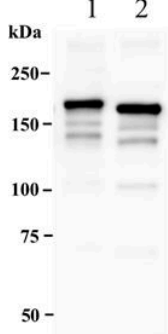

Figure 3. SDS-PAGE and western blot analysis of purified plant-produced cD5 mAb. Purified plant-produced cD5 mAb (lane1) and irrelevant human IgG (lane2). Panels (A), (B), and (C) show SDS-PAGE gradient gel (6-15\%) results of the antibodies under reducing condition with InstantBlue ${ }^{\mathrm{TM}}$, anti-Gamma, and anti-Kappa, respectively. Panels (D), (E), and (F) showed results of 6\% SDS-PAGE gel results of the antibodies under the non-reducing condition with InstantBlue ${ }^{\mathrm{TM}}$, anti-Gamma, and anti-Kappa, respectively.

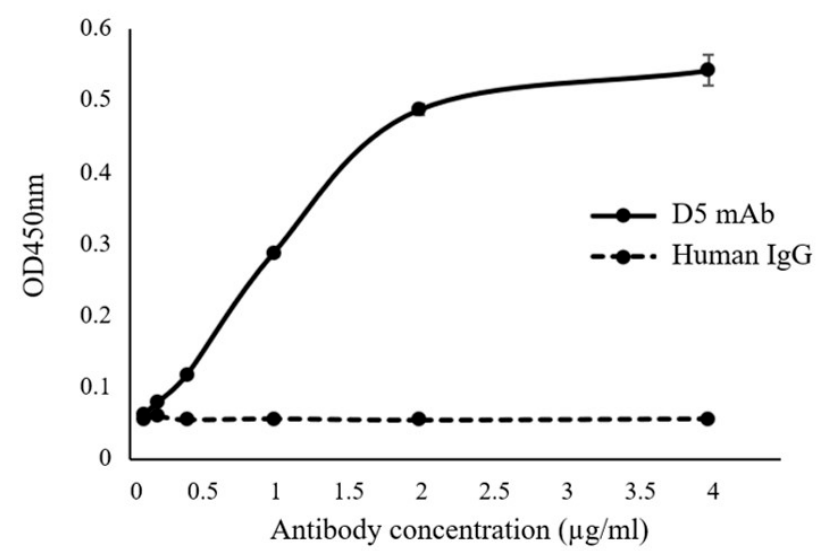

Figure 4. Determination of binding affinity of plant-produced cD5 mAb to synthetic SP70 peptide by ELISA. Synthetic SP70 peptide was used as the coating antigen and irrelevant human IgG was used as a negative control. The representative points are the mean values of triplicate assays conducted at each concentration of the antibodies.

\subsection{Plant-Produced cD5 $m A b$ Efficiently Neutralized EV71}

Plant-produced cD5 mAb was tested in vitro for its ability to inhibit EV71 infection using micro-neutralization assay. Murine D5 antibody served as the positive control in this assay. Figure 5 shows a dose-dependent inhibitory effect of plant-produced cD5 mAb with an IC50 value of $1.53 \mu \mathrm{g} / \mathrm{mL}$. Moreover, there was no significant difference $(p=0.2844 ; p>0.05)$ in the neutralization capacity between the plant-produced cD5 mAb and murine D5 antibody (IC50 value $=0.49 \mu \mathrm{g} / \mathrm{mL}$ ). These results showed that plant-derived $\mathrm{cD} 5 \mathrm{mAb}$ retains the neutralizing activity of murine $\mathrm{D} 5 \mathrm{mAb}$. 


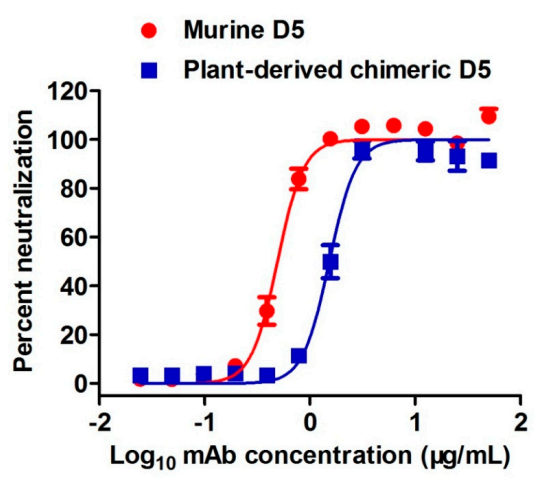

Figure 5. Neutralizing activity of plant-produced cD5 mAb against EV71. One hundred TCID50 of EV71 strain EV71/G082 was mixed with serial two-fold dilutions of plant-produced cD5 or murine D5 antibodies and incubated for $1 \mathrm{~h}$. The mixtures were added to rhabdomyosarcoma cells (RD cells) and incubated for three days. Cell viability was measured, and results were expressed as percent neutralization. Data are expressed as mean \pm SEM of five replicate wells.

\subsection{Plant-Produced cD5 mAb Protected Recipient Mice Against Lethal EV71 Infection}

The therapeutic efficacy of plant-produced cD5 mAb was assessed in a neonatal mouse model of EV71 infection, based on the mouse-adapted EV71 strain, EV71/MAV-W. Groups of 5-day-old ICR mice were infected with a lethal dose of EV71/MAV-W. Twenty-four hours later, a single dose of PBS, $10 \mu \mathrm{g} / \mathrm{g}$ of plant-produced cD5 mAb, or $10 \mu \mathrm{g} / \mathrm{g}$ of murine D5 mAb were administered to mice. Note that in this experiment, murine D5 mAb and PBS were used as positive and negative controls, respectively. After infection, mice in the PBS group developed signs of paralysis gradually and died eventually within 14 days post-infection. In contrast, all mice treated with plant-produced or murine D5 antibodies remained symptom-free, and all of them survived (Figure 6). These results indicated that plant-produced cD5 mAb could protect mice against lethal EV71 infection.

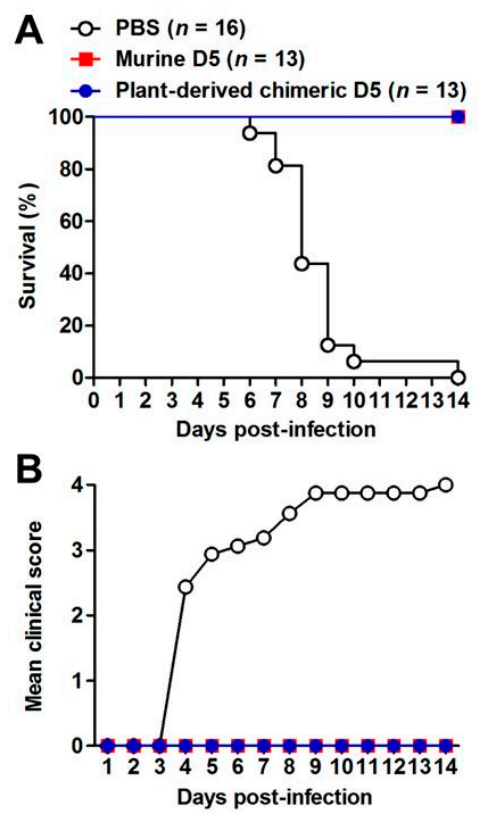

Figure 6. Plant-derived cD5 antibody fully protected mice against EV71 infection. Groups of 5-day-old ICR mice were infected with EV71/MAV-W, and $24 \mathrm{~h}$ later injected with phosphate-buffered saline (PBS), plant-produced cD5 antibody, or murine D5 antibody. The infected mice were monitored daily for 14 days for (A) survival and (B) clinical score. Clinical scores were graded as follows: 0, healthy; 1 , reduced mobility; 2 , limb weakness; 3 , paralysis; and 4, death. The number of mice in each group was indicated in the bracket. 


\section{Discussion}

Despite the severe enterovirus 71 (EV71) outbreaks in Asia, currently, there is no effective treatment [32]. The industrial standard for therapeutic antibody production is the use of mammalian cells [33]. However, the high production cost and limited scalability limit availability of these antibodies for therapeutic use in regions with HFMD outbreak. Several advantages of production of mAbs using the plant platform encouraged the possible utility of this platform in the developing countries, due to low production cost, rapid production, lack of animal and human pathogens, and scalability [34-36]. Several mAbs produced in plants are in clinical trials for tooth decay [37], HIV [38], and cancer [39]. Here, we investigated the possibility of producing a therapeutic $\mathrm{mAb}$ against EV71 in plants.

There are several mAbs specific to EV71, for example, mAb specific to RNA-dependent RNA polymerase [40], mAb binding to EV71 VP1 [20,22,24-26], mAb binding to EV71 VP2 [41], mAb binding to VP3 [42], and others. Among these mAbs, D5 is one of the most potent anti-EV71 neutralizing $\mathrm{mAb}$. It is specific to the highly conserved VP1 GH-loop of EV71 and was shown to have a broad cross-neutralization activity against all tested EV71 strains $[26,27,43]$. Therefore, this mAb has the potential to be an effective treatment for EV71 infection. In the present study, we report the transient expression of chimeric D5 (cD5) mAb in a plant system.

In this study, murine D5 antibody was engineered into a chimeric antibody cD5 to increase the clinical potential of this antibody. The CD5 mAb was expressed at high levels in $N$. benthamiana leaves within six days after agroinfiltration (Figure 2 ) and efficiently assembled into a native IgG molecule (Figure 3). With the codon-optimization, cD5 mAb accumulated at an average of $50 \mu \mathrm{g} / \mathrm{g}$ fresh leaf weight (Figure 2). The results showed that plant-produced cD5 mAb could bind to SP 70 peptide of the VP1 on EV71 (Figure 4) and efficiently neutralize EV71 in vitro (Figure 5), demonstrating that plant-derived $\mathrm{CD} 5 \mathrm{mAb}$ retains the binding and neutralizing activities of murine D5 mAb.

To be considered a therapeutic agent, the plant-made $\mathrm{cD} 5 \mathrm{mAb}$ must have in vivo efficacy. The mouse-adapted EV71 infection in ICR mice caused lethal infection. In this study, the plant-produced cD5 mAb protected all mice from EV71 challenge, similar to murine D5 mAb used as a positive control. To our knowledge, this is the first report on the plant-produced $\mathrm{mAb}$ showing successful protection of mice against EV71 lethal challenge. Our in vivo results showed the potential of plant-produced $\mathrm{cD} 5 \mathrm{mAb}$ as an efficacious post-exposure treatment. In conclusion, plant-produced cD5 mAb has the potential to be developed further for use as EV71 diagnostic and post-exposure prophylactic agent during HFMD outbreaks.

\section{Materials and Methods}

\subsection{Gene Construct}

The variable region gene sequences of D5 heavy chain (VH) and light chain (VL) were codon-optimized for using GeneArt and synthesized. To construct heavy chain of cD5 antibody, the VH gene and constant region of human IgG1 heavy chain $(\mathrm{CH})$ was cut with XbaI/NheI and NheI/SacI, respectively, and inserted into geminiviral vector, resulting in pBYD5-HC. For the light chain of cD5 antibody, the VL gene and constant region of human kappa light chain (CL) was cut with XbaI/AfIII and AflII/SacI, respectively, and inserted into geminiviral vector to make pBYD5-LC. Each construct was transformed into Agrobacterium tumefaciens strain GV3101.

\subsection{Protein Expression, Extraction and Quantification}

Six to eight weeks-old of $N$. benthamiana plants were co-infiltrated with an equal amount of two Agrobacterium GV3101 strains containing pBYD5-HC or pBYD5-LC, at a final OD600 of 0.2. For a time-course of expression experiment, leaves were harvested on days-2, $-4,-6,-8$, and -10 after infiltration. Leaf samples were extracted with 1x PBS (phosphate-buffered saline: $137 \mathrm{mM} \mathrm{NaCl}$, $\left.2.7 \mathrm{mM} \mathrm{KCl}, 4.3 \mathrm{mM} \mathrm{Na}_{2} \mathrm{HPO}_{4}, 1.47 \mathrm{mM} \mathrm{KH}_{2} \mathrm{PO}_{4}\right)$ at $\mathrm{pH}$ 7.4. The plant-produced cD5 antibody was quantified by ELISA in a 96-well plate (Greiner Bio-One $\mathrm{GmbH}$, Kremsmünster, Austria) coated 
with $50 \mu \mathrm{L}$ of anti-human IgG Fc fragment (Abcam, Cambridge, UK) (diluted 1:1000 in 1X PBS) and incubated overnight at $4{ }^{\circ} \mathrm{C}$. The plate was washed three times with $1 \mathrm{X}$ PBS-T (1X PBS plus $0.05 \%$ Tween-20) and blocked with 5\% skim milk in $1 \mathrm{X}$ PBS for $2 \mathrm{~h}$ at $37^{\circ} \mathrm{C}$. After washing three times with 1X PBS-T, the diluted plant-produced CD5 antibody extracts and human IgG1 kappa isotype antibody (Abcam, Cambridge, UK) were added to the wells and incubated at $37^{\circ} \mathrm{C}$ for $2 \mathrm{~h}$. The plate was washed three times with 1X PBS-T and incubated with $50 \mu \mathrm{L}$ of HRP-conjugated anti-human kappa (The Binding Site, Birmingham, UK) at $37^{\circ} \mathrm{C}$ for $1 \mathrm{~h}$. The plate was washed and developed using TMB mixture (Promega, Fitchburg, WI, USA). The reaction was stopped by $1 \mathrm{M}_{2} \mathrm{SO}_{4}$ and absorbance was measured at $450 \mathrm{~nm}$ using a 96-well microplate reader (BMG Labtech, Ortenberg, Germany).

\subsection{Purification}

Infiltrated $N$. benthamiana leaves were extracted with $1 \times$ PBS at pH 7.5 using a blender and centrifuged at $26,000 \mathrm{X} g$ for $30 \mathrm{~min}$. The supernatant was filtered with a $0.45 \mu \mathrm{m}$ membrane filter and loaded onto a protein-A bead column. The column was washed with ten-bed volumes of PBS pH 7.5. The bound protein was eluted with $0.1 \mathrm{M}$ glycine, $\mathrm{pH} 2.7$, and rapidly neutralized to $\mathrm{pH} 7.5$ with $1.5 \mathrm{M}$ Tris-HCL pH 8.8. The purified plant-produced cD5 antibody was analyzed using SDS PAGE and western blot.

\subsection{SDS-PAGE and Western Blot Analysis}

In the non-reducing condition, the purified plant-produced cD5 antibody and human IgG control antibody (Abcam, Cambridge, UK) were mixed with the non-reducing loading dye (125 mM Tris- $\mathrm{HCl}$ $\mathrm{pH} 6.8,12 \%(w / v)$ SDS, $10 \%(v / v)$ glycerol, and $0.001 \%(w / v)$ bromophenol blue) and separated using $6 \%$ sodium dodecyl sulfate-polyacrylamide gel electrophoresis (SDS-PAGE). In the reducing condition, the antibodies were mixed with the loading dye (non-reducing loading dye with $22 \%(v / v)$ $\beta$-mercaptoethanol) and separated on 6-15\% SDS-PAGE. Proteins were stained with InstantBlue (TM) (Expedeon, Cambridge, UK). For western blot analysis, proteins were electrophoretically transferred to a nitrocellulose membrane (Biorad, California, USA) and blocked with 5\% skim milk in 1X PBS. The membranes were probed with HRP-conjugated anti-human IgG gamma chain (The Binding Site, Birmingham, UK) or with HRP-conjugated anti-human kappa (The Binding Site, Birmingham, UK) and developed by chemiluminescence using ECL plus detection reagent (Abcam, Cambridge, UK).

\subsection{Binding Assay}

Plant-produced cD5 antibody binding was determined by ELISA assay using a specific peptide. A 96-well plate was coated with $50 \mu \mathrm{L} /$ well $(10 \mu \mathrm{g} / \mathrm{mL})$ of SP70 peptide (YPTFGEHKQEKDLEY) in PBS buffer and incubated overnight at $4{ }^{\circ} \mathrm{C}$. Next, the plate was washed three times with PBST buffer and blocked with $200 \mathrm{~mL}$ of $5 \%$ nonfat milk powder in PBS buffer for $2 \mathrm{~h}$ at $37^{\circ} \mathrm{C}$. Subsequently, $50 \mu \mathrm{L} /$ well of diluted cD5 antibody samples in PBS buffer and unrelated human IgG antibody (Abcam, Cambridge, UK), used as a negative control, were added and incubated for $2 \mathrm{~h}$ at $37^{\circ} \mathrm{C}$. Later they were incubated with an anti-human kappa chain-HRP antibody (The Binding Site, Birmingham, UK) in PBS buffer for $1 \mathrm{~h}$ at $37^{\circ} \mathrm{C}$. The ELISA plate was developed with $50 \mu \mathrm{L} /$ well of TMB mixture (Promega, Fitchburg, WI, USA) and incubated for $2 \mathrm{~min}$. The reactions were stopped by $50 \mu \mathrm{L} /$ well of $1 \mathrm{M} \mathrm{H}_{2} \mathrm{SO}_{4}$ and absorbance was measured at $450 \mathrm{~nm}$ using a 96-well microplate reader (BMG Labtech, Ortenberg, Germany).

\subsection{Neutralization Assay}

Neutralizing activity of plant-produced cD5 antibody against EV71 clinical strain EV71/G082 was measured using the micro-neutralization assay as described previously [44]. After incubation for three days, cell viability was measured using the CellTiter-Glo 2.0 assay kit (Promega, Fitchburg, WI, USA) following the manufacturer's protocol. The percentage of neutralization was calculated as follows: $100 \times$ (luminescence of the given sample-luminescence of the virus-only sample)/(luminescence of the cell-only sample-luminescence of the virus-only sample). Half-maximal inhibitory concentration 
(IC50) of plant-produced cD5 antibody was determined using variable-slope nonlinear regression analysis by GraphPad Prism software.

\subsection{In Vivo Protection Assay}

For evaluating the therapeutic efficacy of plant-produced cD5 mAb, groups of 5-day-old ICR mice were inoculated intraperitoneally (i.p.) with $3.4 \times 10^{4}$ TCID50 (Median Tissue Culture Infectious Dose) of mouse-adapted EV71 strain EV71/MAV-W [45]. One day later, the infected mice were injected i.p. with PBS, plant-produced cD5 antibody ( $10 \mu \mathrm{g} / \mathrm{g}$ body weight), or murine D5 antibody ( $10 \mu \mathrm{g} / \mathrm{g}$ body weight). After infection, the mice were monitored daily for 14 days for survival and clinical score. Clinical scores were graded as follows: 0 , healthy; 1 , reduced mobility; 2 , limb weakness; 3 , paralysis; and 4, death. All animal studies were approved by the Institional Animal Care and Use Committee at the Institut Pasteur of Shanghai, and the project identification code was 20170324-1.

\subsection{Statistical Analysis}

All statistical analyses were performed using GraphPad Prism version 5.

Author Contributions: Z.H. and W.P. conceived and designed the study. K.R., Z.C. and K.S. performed the experiment. All the authors analyzed the data and wrote the manuscript.

Funding: This study was supported by Thailand Research Fund grant No. RSA6280006.

Acknowledgments: K.R. was supported by the Ratchadaphiseksomphot Fund, Chulalongkorn University for the postdoctoral Fellowship.

Conflicts of Interest: The authors declare no conflict of interest.

\section{References}

1. Chen, Y.; Badaruddin, H.; Lee, V.J.; Cutter, J.; Cook, A.R. The effect of school closure on hand, foot, and mouth disease transmission in Singapore: A Modeling Approach. Am. J. Trop. Med. Hyg. 2018, 99, 1625-1632. [CrossRef]

2. Hoang, M.T.V.; Nguyen, T.A.; Tran, T.T.; Vu, T.T.H.; Le, N.T.N.; Nguyen, T.H.N.; Le, T.H.N.; Nguyen, T.T.H.; Nguyen, T.H.; Le, N.T.N.; et al. Clinical and aetiological study of hand, foot and mouth disease in southern Vietnam, 2013-2015: Inpatients and outpatients. Int. J. Infect. Dis. 2019, 80, 1-9. [CrossRef] [PubMed]

3. Ooi, M.H.; Wong, S.C.; Lewthwaite, P.; Cardosa, M.J.; Solomon, T. Clinical features, diagnosis, and management of enterovirus 71. Lancet Neurol. 2010, 9, 1097-1105. [CrossRef]

4. Huang, C.C.; Liu, C.C.; Chang, Y.C.; Chen, C.Y.; Wang, S.T.; Yeh, T.F. Neurologic complications in children with enterovirus 71 infection. N. Engl. J. Med. 1999, 341, 936-942. [CrossRef] [PubMed]

5. Dong, C.; Wang, J.; Liu, L.; Zhao, H.; Shi, H.; Zhang, Y.; Jiang, L.; Li, Q. Optimized development of a candidate strain of inactivated EV71 vaccine and analysis of its immunogenicity in rhesus monkeys. Hum. Vaccin. 2010, 6, 1028-1037. [CrossRef] [PubMed]

6. Liu, L.; Zhang, Y.; Wang, J.; Zhao, H.; Jiang, L.; Che, Y.; Shi, H.; Li, R.; Mo, Z.; Huang, T.; et al. Study of the integrated immune response induced by an inactivated EV71 vaccine. PLoS ONE 2013, 8, e54451. [CrossRef] [PubMed]

7. Dong, C.; Liu, L.; Zhao, H.; Wang, J.; Liao, Y.; Zhang, X.; Na, R.; Liang, Y.; Wang, L.; Li, Q. Immunoprotection elicited by an enterovirus type 71 experimental inactivated vaccine in mice and rhesus monkeys. Vaccine 2011, 29, 6269-6275. [CrossRef] [PubMed]

8. Bek, E.J.; Hussain, K.M.; Phuektes, P.; Kok, C.C.; Gao, Q.; Cai, F.; Gao, Z.; McMinn, P.C. Formalin-inactivated vaccine provokes cross-protective immunity in a mouse model of human enterovirus 71 infection. Vaccine 2011, 29, 4829-4838. [CrossRef]

9. Cai, Y.; Ku, Z.; Liu, Q.; Leng, Q.; Huang, Z. A combination vaccine comprising of inactivated enterovirus 71 and coxsackievirus A16 elicits balanced protective immunity against both viruses. Vaccine 2014, 32, 2406-2412. [CrossRef] 
10. Chiu, C.H.; Chu, C.; He, C.C.; Lin, T.Y. Protection of neonatal mice from lethal enterovirus 71 infection by maternal immunization with attenuated Salmonella enterica serovar Typhimurium expressing VP1 of enterovirus 71. Microbes Infect. 2006, 8, 1671-1678. [CrossRef]

11. Arita, M.; Nagata, N.; Iwata, N.; Ami, Y.; Suzaki, Y.; Mizuta, K.; Iwasaki, T.; Sata, T.; Wakita, T.; Shimizu, H. An attenuated strain of enterovirus 71 belonging to genotype a showed a broad spectrum of antigenicity with attenuated neurovirulence in cynomolgus monkeys. J. Virol. 2007, 81, 9386-9395. [CrossRef] [PubMed]

12. Chung, Y.C.; Ho, M.S.; Wu, J.C.; Chen, W.J.; Huang, J.H.; Chou, S.T.; Hu, Y.C. Immunization with virus-like particles of enterovirus 71 elicits potent immune responses and protects mice against lethal challenge. Vaccine 2008, 26, 1855-1862. [CrossRef] [PubMed]

13. Wu, C.N.; Lin, Y.C.; Fann, C.; Liao, N.S.; Shih, S.R.; Ho, M.S. Protection against lethal enterovirus 71 infection in newborn mice by passive immunization with subunit VP1 vaccines and inactivated virus. Vaccine 2001, 20, 895-904. [CrossRef]

14. Chung, C.Y.; Chen, C.Y.; Lin, S.Y.; Chung, Y.C.; Chiu, H.Y.; Chi, W.K.; Lin, Y.L.; Chiang, B.L.; Chen, W.J.; $\mathrm{Hu}$, Y.C. Enterovirus 71 virus-like particle vaccine: Improved production conditions for enhanced yield. Vaccine 2010, 28, 6951-6957. [CrossRef] [PubMed]

15. Wang, X.; Ku, Z.; Dai, W.; Chen, T.; Ye, X.; Zhang, C.; Zhang, Y.; Liu, Q.; Jin, X.; Huang, Z. A bivalent virus-like particle based vaccine induces a balanced antibody response against both enterovirus 71 and norovirus in mice. Vaccine 2015, 33, 5779-5785. [CrossRef]

16. Foo, D.G.; Alonso, S.; Chow, V.T.; Poh, C.L. Passive protection against lethal enterovirus 71 infection in newborn mice by neutralizing antibodies elicited by a synthetic peptide. Microbes Infect. 2007, 9, 1299-1306. [CrossRef]

17. Liu, J.N.; Wang, W.; Duo, J.Y.; Hao, Y.; Ma, C.M.; Li, W.B.; Lin, S.Z.; Gao, X.Z.; Liu, X.L.; Xu, Y.F.; et al. Combined peptides of human enterovirus 71 protect against virus infection in mice. Vaccine 2010, 28, 7444-7451. [CrossRef]

18. Cao, R.; Han, J.; Qin, E.; Qin, C. [Mechanism of intravenous immunoglobulin therapy for severe hand-foot-mouth disease: A review]. Sheng Wu Gong Cheng Xue Bao 2011, 27, 712-716.

19. Elgundi, Z.; Reslan, M.; Cruz, E.; Sifniotis, V.; Kayser, V. The state-of-play and future of antibody therapeutics. Adv. Drug Deliv. Rev. 2017, 122, 2-19. [CrossRef]

20. Lim, X.F.; Jia, Q.; Khong, W.X.; Yan, B.; Premanand, B.; Alonso, S.; Chow, V.T.; Kwang, J. Characterization of an isotype-dependent monoclonal antibody against linear neutralizing epitope effective for prophylaxis of enterovirus 71 infection. PLoS ONE 2012, 7, e29751. [CrossRef]

21. Kiener, T.K.; Jia, Q.; Meng, T.; Chow, V.T.; Kwang, J. A novel universal neutralizing monoclonal antibody against enterovirus 71 that targets the highly conserved "knob" region of VP3 protein. PLoS Negl. Trop. Dis. 2014, 8, e2895. [CrossRef] [PubMed]

22. Chang, G.H.; Luo, Y.J.; Wu, X.Y.; Si, B.Y.; Lin, L.; Zhu, Q.Y. Monoclonal antibody induced with inactived EV71-Hn2 virus protects mice against lethal EV71-Hn2 virus infection. Virol. J. 2010, 7, 106. [CrossRef] [PubMed]

23. Liu, C.C.; Chou, A.H.; Lien, S.P.; Lin, H.Y.; Liu, S.J.; Chang, J.Y.; Guo, M.S.; Chow, Y.H.; Yang, W.S.; Chang, K.H.; et al. Identification and characterization of a cross-neutralization epitope of Enterovirus 71. Vaccine 2011, 29, 4362-4372. [CrossRef] [PubMed]

24. Deng, Y.Q.; Ma, J.; Xu, L.J.; Li, Y.X.; Zhao, H.; Han, J.F.; Tao, J.; Li, X.F.; Zhu, S.Y.; Qin, E.D.; et al. Generation and characterization of a protective mouse monoclonal antibody against human enterovirus 71. Appl. Microbiol. Biotechnol. 2015, 99, 7663-7671. [CrossRef]

25. Lin, T.; Xianyu, L.; Lyu, S. Monoclonal neutralizing antibodies against EV71 screened from mice immunized with yeast-produced virus-like particles. Virol. Sin. 2015, 30, 208-213. [CrossRef]

26. Ku, Z.; Ye, X.; Shi, J.; Wang, X.; Liu, Q.; Huang, Z. Single Neutralizing Monoclonal Antibodies Targeting the VP1 GH Loop of Enterovirus 71 Inhibit both Virus Attachment and Internalization during Viral Entry. J. Virol. 2015, 89, 12084-12095. [CrossRef]

27. Ye, X.; Fan, C.; Ku, Z.; Zuo, T.; Kong, L.; Zhang, C.; Shi, J.; Liu, Q.; Chen, T.; Zhang, Y.; et al. Structural Basis for Recognition of Human Enterovirus 71 by a Bivalent Broadly Neutralizing Monoclonal Antibody. PLoS Pathog. 2016, 12, e1005454. [CrossRef]

28. Chen, Q.; Davis, K.R. The potential of plants as a system for the development and production of human biologics. F1000Reserch 2016, 5. [CrossRef] 
29. Lai, H.; Engle, M.; Fuchs, A.; Keller, T.; Johnson, S.; Gorlatov, S.; Diamond, M.S.; Chen, Q. Monoclonal antibody produced in plants efficiently treats West Nile virus infection in mice. Proc. Natl. Acad. Sci. USA 2010, 107, 2419-2424. [CrossRef]

30. Huang, Z.; Phoolcharoen, W.; Lai, H.; Piensook, K.; Cardineau, G.; Zeitlin, L.; Whaley, K.J.; Arntzen, C.J.; Mason, H.S.; Chen, Q. High-level rapid production of full-size monoclonal antibodies in plants by a single-vector DNA replicon system. Biotechnol. Bioeng. 2010, 106, 9-17. [CrossRef]

31. Both, L.; van Dolleweerd, C.; Wright, E.; Banyard, A.C.; Bulmer-Thomas, B.; Selden, D.; Altmann, F.; Fooks, A.R.; Ma, J.K. Production, characterization, and antigen specificity of recombinant 62-71-3, a candidate monoclonal antibody for rabies prophylaxis in humans. FASEB J. 2013, 27, 2055-2065. [CrossRef] [PubMed]

32. Mao, Q.Y.; Wang, Y.; Bian, L.; Xu, M.; Liang, Z. EV71 vaccine, a new tool to control outbreaks of hand, foot and mouth disease (HFMD). Expert Rev. Vaccines 2016, 15, 599-606. [CrossRef] [PubMed]

33. Templar, A.; Marsh, D.; Nesbeth, D.N. A synthetic biology standard for Chinese Hamster Ovary cell genome monitoring and contaminant detection by polymerase chain reaction. Springerplus 2016, 5, 1510. [CrossRef] [PubMed]

34. Chen, Q. Plant-made vaccines against West Nile virus are potent, safe, and economically feasible. Biotechnol. J. 2015, 10, 671-680. [CrossRef]

35. Nandi, S.; Kwong, A.T.; Holtz, B.R.; Erwin, R.L.; Marcel, S.; McDonald, K.A. Techno-economic analysis of a transient plant-based platform for monoclonal antibody production. MAbs 2016, 8, 1456-1466. [CrossRef]

36. Chen, Q.; Lai, H.; Hurtado, J.; Stahnke, J.; Leuzinger, K.; Dent, M. Agroinfiltration as an Effective and Scalable Strategy of Gene Delivery for Production of Pharmaceutical Proteins. Adv. Tech. Biol. Med. 2013, 1. [CrossRef]

37. Weintraub, J.A.; Hilton, J.F.; White, J.M.; Hoover, C.I.; Wycoff, K.L.; Yu, L.; Larrick, J.W.; Featherstone, J.D. Clinical trial of a plant-derived antibody on recolonization of mutans streptococci. Caries Res. 2005, 39, 241-250. [CrossRef]

38. Ma, J.K.; Drossard, J.; Lewis, D.; Altmann, F.; Boyle, J.; Christou, P.; Cole, T.; Dale, P.; van Dolleweerd, C.J.; Isitt, V.; et al. Regulatory approval and a first-in-human phase I clinical trial of a monoclonal antibody produced in transgenic tobacco plants. Plant Biotechnol. J. 2015, 13, 1106-1120. [CrossRef]

39. Tuse, D.; Ku, N.; Bendandi, M.; Becerra, C.; Collins, R., Jr.; Langford, N.; Sancho, S.I.; Lopez-Diaz de Cerio, A.; Pastor, F.; Kandzia, R.; et al. Clinical Safety and Immunogenicity of Tumor-Targeted, Plant-Made Id-KLH Conjugate Vaccines for Follicular Lymphoma. Biomed. Res. Int. 2015, 2015, 648143. [CrossRef]

40. Li, Y.; Yu, J.; Qi, X.; Yan, H. Monoclonal antibody against EV71 3D(pol) inhibits the polymerase activity of RdRp and virus replication. BMC Immunol. 2019, 20, 6. [CrossRef]

41. Thanongsaksrikul, J.; Srimanote, P.; Tongtawe, P.; Glab-Ampai, K.; Malik, A.A.; Supasorn, O.; Chiawwit, P.; Poovorawan, Y.; Chaicumpa, W. Identification and production of mouse scFv to specific epitope of enterovirus-71 virion protein-2 (VP2). Arch. Virol. 2018, 163, 1141-1152. [CrossRef] [PubMed]

42. Jia, Q.; Ng, Q.; Chin, W.; Meng, T.; Chow, V.T.K.; Wang, C.I.; Kwang, J.; He, F. Effective in vivo therapeutic IgG antibody against VP3 of enterovirus 71 with receptor-competing activity. Sci. Rep. 2017, 7, 46402. [CrossRef] [PubMed]

43. Ku, Z.; Shi, J.; Liu, Q.; Huang, Z. Development of murine monoclonal antibodies with potent neutralization effects on enterovirus 71. J. Virol. Methods 2012, 186, 193-197. [CrossRef] [PubMed]

44. Ku, Z.; Ye, X.; Huang, X.; Cai, Y.; Liu, Q.; Li, Y.; Su, Z.; Huang, Z. Neutralizing antibodies induced by recombinant virus-like particles of enterovirus 71 genotype $C 4$ inhibit infection at pre- and post-attachment steps. PLoS ONE 2013, 8, e57601. [CrossRef]

45. Zhang, C.; Ku, Z.; Liu, Q.; Wang, X.; Chen, T.; Ye, X.; Li, D.; Jin, X.; Huang, Z. High-yield production of recombinant virus-like particles of enterovirus 71 in Pichia pastoris and their protective efficacy against oral viral challenge in mice. Vaccine 2015, 33, 2335-2341. [CrossRef]

(C) 2019 by the authors. Licensee MDPI, Basel, Switzerland. This article is an open access article distributed under the terms and conditions of the Creative Commons Attribution (CC BY) license (http://creativecommons.org/licenses/by/4.0/). 